\title{
'Working as a community dentist is fantastic'
}

\begin{abstract}
Linzi Maybin, originally from Ballymena in Ireland, is a community dentist in Yorkshire and the founder of Happy Teeth Outreach, a voluntary, non-profitable educational programme which partners with Health Education England to educate foundation dentists in Yorkshire and Humber. Happy Teeth Outreach aims to improve oral health for children and young people with additional needs in special educational settings and children living in the UK affected by human trafficking and the refugee crisis.
\end{abstract}

I

tend to get up at $7 \mathrm{am}$, grab a croissant for breakfast and usually drive to work. When I'm feeling energetic, I use my push scooter which tends to amuse my dental colleagues and patients.

Working as a community dentist is fantastic. No day is the same and it is so rewarding. I get to work with patients with complex medical needs, learning disabilities and physical disabilities.

I have always been passionate about community outreach and helping vulnerable groups both in and outside of dentistry. For many years, I have been a
Like so many organisations during the pandemic, youth centres closed their doors to face-to-face events. But also, all of Happy Teeth Outreach's school sessions were postponed. With the reduction of face-toface outreach programmes, there is rising concern for the mental health of CYP. At the start of lockdown, Child \& Adolescent Mental Health Services (CAMHS) saw a significant reduction in their referral rates. This decrease in referrals may mean CYP are less visible to youth centres and CAMHS, and could mean that young people have fewer opportunities to voice their struggles.

\section{'From day one of dental school I knew I wanted to use dentistry to help families from deprived and challenging backgrounds.'}

youth worker across a variety of settings: in schools, community centres, young offenders' institutes and council estates. It was through this youth work and seeing the transformational and positive change in the lives of these young people from deprived backgrounds that inspired me. This inspiration meant that from day one of dental school I knew I wanted to use dentistry to help families from deprived and challenging backgrounds.

As a youth leader and community dentist, I saw the impact poor dental health had on these children and young people (CYP). Subsequently, this was one of the catalysts in setting up Happy Teeth Outreach. I became very interested in wanting to champion good oral health for this often overlooked group to see what could be done to develop a more socially inclusive oral health network to improve their lives.
Personally, I have seen the importance of youth centres in my own life when I was a teenager and how they help young people to stay off the streets and out of trouble.

With Happy Teeth Outreach, I have worked hard to maintain strong relationships with the schools, youth centres and refugee clinics during the pandemic and still provide online teaching, resources and support to our partner organisations.

My immediate response to the pandemic through Happy Teeth Outreach was the development of our community partnership work for CYP living in the UK affected by human trafficking and the refugee crisis.

In December, through liaising with a refugee centre, I organised a Christmas giveaway for over 70 children living in Bradford that have been affected by human trafficking and the refugee crisis. The volunteer dentists and therapists delivered

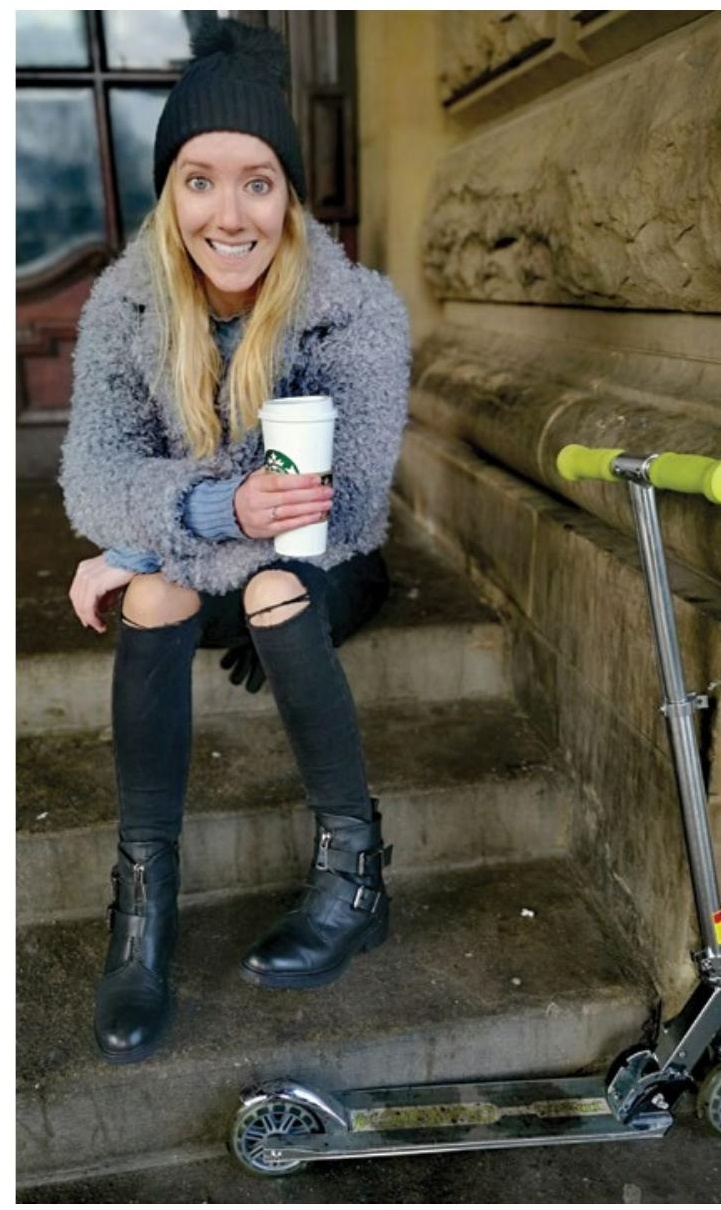

Christmas presents and oral health packs to these children [pictured]. All families were extremely grateful for the delivery. The sad thing is that for some of these children this may have been the only Christmas present they received. It was an amazing day, incredibly rewarding and fulfilling. It was great for our team to see the positive difference they were making in the lives of these children.

One family that had survived human trafficking were too fearful to open their door to collect the presents. Despite the language barrier, a volunteer from the team communicated in their language through 
14 the letter box to reassure them they were safe and we were delivering Christmas presents. Thankfully, the family accepted the presents and dental packs and were extremely grateful.

This is a reminder of the post-traumatic anxieties that can impact survivors of human trafficking. This can sometimes be the most challenging thing for me - working closely with communities who have suffered considerable hardship. Through partnering with other organisations, it's reassuring to know their healthcare and social housing needs are being met.

I firmly believe in stepping forward and reaching out to the communities we live in. It's about so much more than dentistry. To inspire life changes through a relational outreach approach personally has been the most rewarding and fulfilling part of my dental career. Dental outreach programmes help to improve oral health and dental access by tackling difficult issues such as barriers to education and healthcare access.

COVID-19 has resulted in a very different way of life for me outside of work. For now,

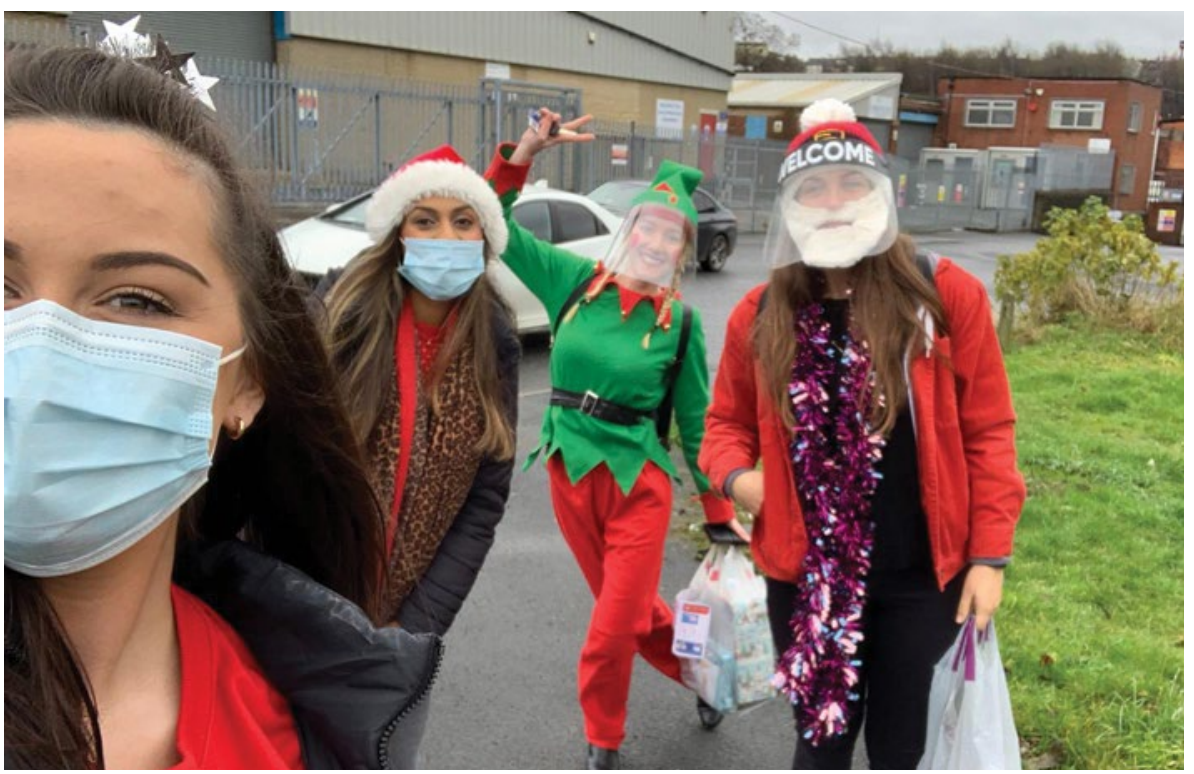

my weekends and evenings are filled with FaceTime, Zoom quizzes, non-essential shopping (depending on the tiers of course), Costa takeaway and lots of socially distanced walks.

This year, I would love to go travelling again when the restrictions are eased.
If I hadn't gone into dentistry, my plan B would have been to pursue dancing, but if I'm honest I'd secretly love to be a CBeebies presenter. I'm always that person at kids' birthday parties leading the games. I've done a lot of work with children and love creating hype with a bit of magic and Disney. 